\title{
THE MECHANICAL PROPERTIES AND FATIGUE PREDICTION OF A NEW GENERATION OF OSTEOSYNTHESIS DEVICES
}

\author{
DRÁTOVSKÁ Veronika ${ }^{*}$, SEDLÁČEK Radek ${ }^{1}$, PADOVEC Zdeněk ${ }^{1}$, RŮŽIČKA \\ Pavel $^{1}$, KRATOCHVÍL Adam ${ }^{1}$ \\ ${ }^{I}$ Czech Technical University in Prague, Faculty of Mechanical Engineering, Department of Mechanics, \\ Biomechanics and Mechatronics, Technická 4, 16000 Praha 6, Czech Republic, \\ e-m ail: veronika.dratovska@fs.cvut.cz.
}

\begin{abstract}
The aim of the study was to predict the fatigue life of metallic bone plates employing SIMULIA fesafe software. Two materials commonly used for surgical implants were subjected to investigation: 1.4441 (ASTM F138) stainless steel for implants and Ti6Al4V ELI (ASTM F136) titanium alloy. The material parameters of the two materials were determined from experimental research. Four-point bending fatigue testing was conducted on two generations of bone plates in order to allow for the comparison of the prediction results with the measured data from the experiments.
\end{abstract}

KEYWORDS: bone plates, fatigue prediction, fe-safe, four-point bending fatigue test

\section{Introduction}

Bone plates are subjected to relatively high stress in human body applications that may lead to the exceeding of the ultimate strength of the material or, more likely, to fatigue failure [1]. The failure of a bone plate may result in additional injury and further complications for the patient and may lead to significant supplementary costs due to the need for reoperation [2]. Therefore, new products must be tested so as to determine the degree of fatigue endurance. However, the conducting of fatigue experiments is expensive and time consuming; moreover, the new product development process usually involves the testing of several prototypes with differing geometries and their comparison in terms of their fatigue properties. In such cases, the finite element method (FEM) is frequently employed in order to provide solutions to engineering issues [3], including biomechanical problems [4]. Hence, we decided to investigate whether it is possible to reliably predict the fatigue life of bone plates employing FEM-based calculations.

The article focuses on the prediction of fatigue via application of SIMULIA fe-safe software. Four-point bending fatigue and static tensile testing were performed so as to determine the material properties, the results of which were then used in the fatigue analysis. Two generations of bone plates for proximal humerus fractures were also subjected to fatigue testing, thus allowing for the comparison of the fe-safe fatigue analysis results with the experimentally-determined data.

\section{Methods and materials}

The methodology of the four-point bending test was based on the ASTM F382 standard [5], which provides a description of the static and cyclical testing of metallic bone plates. Firstly, the static four-point bending test was performed in order to determine suitable loading levels for the fatigue four-point bending test. Subsequently, load-controlled high- 
cycle fatigue testing was conducted at several loading levels. The applied force had a sinusoidal course with a minimum force equal to $10 \%$ of the maximum force (the $R$ ratio equaled 0.1). The fatigue test involved the cyclical loading of the samples until failure was achieved. The number of cycles each of the samples required prior to failure and the respective loading level was recorded.

The four-point bending fatigue test employing flat samples with rectangular crosssection (see Fig. 1 A) was performed in order to determine the properties of the materials. The experiment provided information on the number of cycles prior to failure and the force amplitudes as calculated from the maximum and minimum loading forces. In order to attain an $S$ - $N$ curve (the stress amplitude versus the number of cycles curve), the stress amplitudes were calculated from the force amplitudes using the equation for the maximum stress in bent samples with rectangular cross-sections. The dimensions measured for every sample prior to testing were used for the calculation of the stress amplitude. Basquin's model was applied, represented by equation (1), so as to mathematically describe the $S-N$ curve. This model was chosen since parameters thereof (the fatigue strength coefficient $\sigma_{f}^{\prime}$ and the fatigue strength exponent $b$ ) are used in fe-safe software. The Basquin's model parameters were computed from the measured data via the application of linear regression.

$$
\sigma_{a}=\sigma_{f}^{\prime}(2 N)^{b}
$$

Four-point bending static and fatigue tests were also conducted for the two generations of bone plates for proximal humerus fractures (see Fig. $1 \mathrm{~B}, \mathrm{C}$ ). The resulting data was then used to verify the fatigue life as predicted by the fe-safe software.
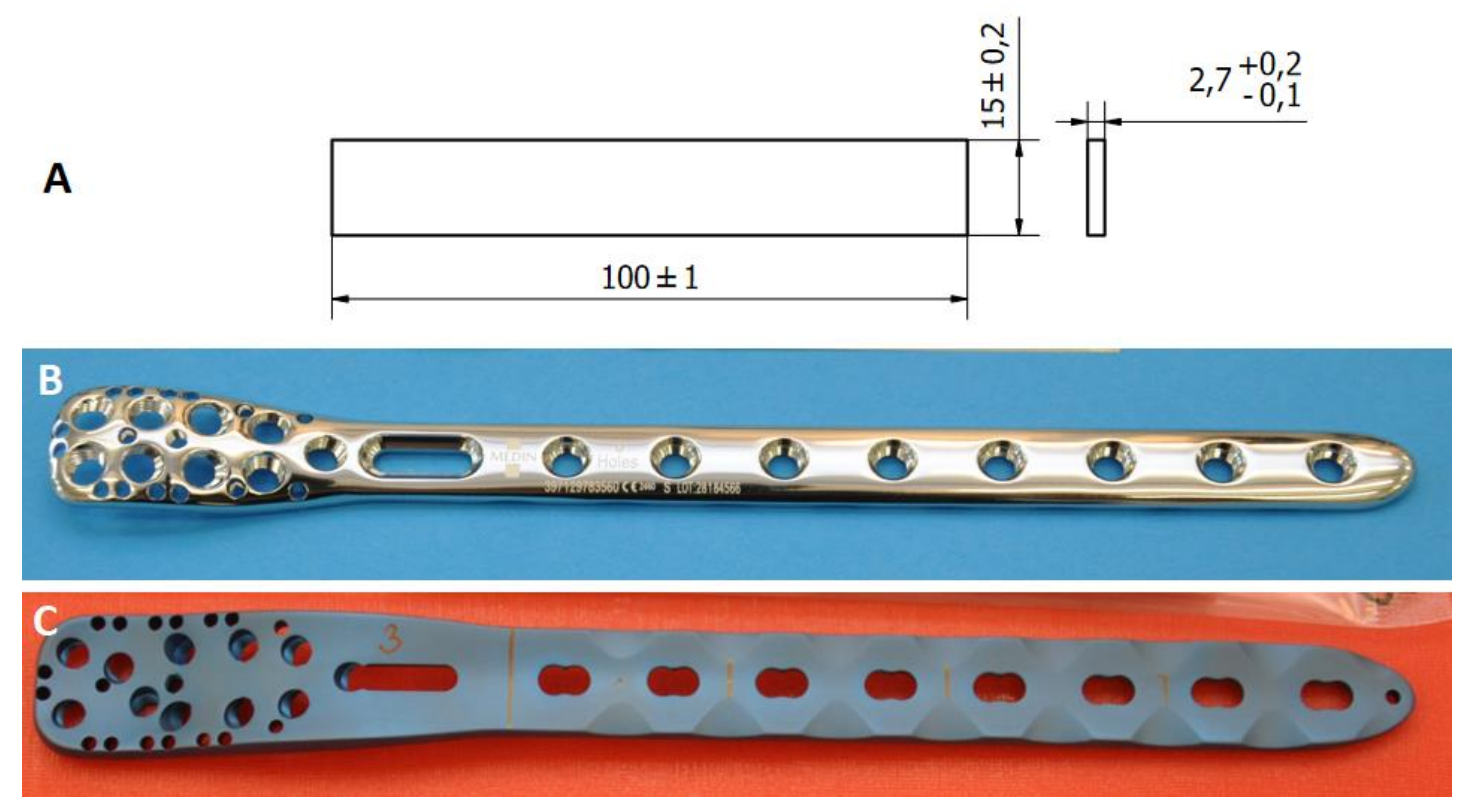

Fig. 1 A Dimensions of the flat sample for the four-point bending test, B stainless steel bone plate of the first generation, $\mathbf{C}$ titanium alloy bone plate of the second generation.

The uniaxial static tensile test was conducted so as to determine the elastic modulus $E$ and the ultimate tensile strength $R_{m}$ of the investigated materials. The tensile test methodology was based on the ČSN EN ISO 6892-1 standard [6]. All the experiments described above were performed using samples made of 1.4441 (ASTM F138) stainless steel for implants [7]. and Ti6A14V ELI (ASTM F136) titanium alloy [8]. Both materials are commonly used for the manufacture of orthopedic implants. 
The data obtained from the experiments was subsequently used to define the material parameters in fe-safe software. However, the data required further adjustments so as to be compatible with the software. The experiments were conducted applying $R$ ratio equal to 0.1 ; however, fe-safe requires data on the material for fully-reversed cycle (an $R$ ratio equal to -1). Therefore, it was necessary to convert the measured parameters to the equivalent of the fullyreversed cycle. Walker's equation [9] was applied for the computation of the new Basquin model parameters. Since not all the required fatigue parameters were obtained from the experiments, Seeger's method [10], which estimates fatigue properties using the ultimate tensile strength and the modulus of elasticity, was applied to determine the remaining parameters (the strain hardening coefficient $K^{\prime}$, the strain hardening exponent $n^{\prime}$, the fatigue ductility coefficient $\varepsilon_{f}^{\prime}$, and the fatigue ductility exponent $c$ ).

The fatigue analysis based on the elastic FEA (Finite Element Analysis) results was applied in the fe-safe software. The static analysis required to gather these results was performed in Abaqus software. Models of three generations of bone plates (see Fig. 2) were created and loaded in the four-point bending mode in the same configuration as in the experiments. Each bone plate was loaded up to $1000 \mathrm{~N}$ in Abaqus. The results of the Abaqus analysis (in *.odb file format) were used as input data for the fe-safe processing.

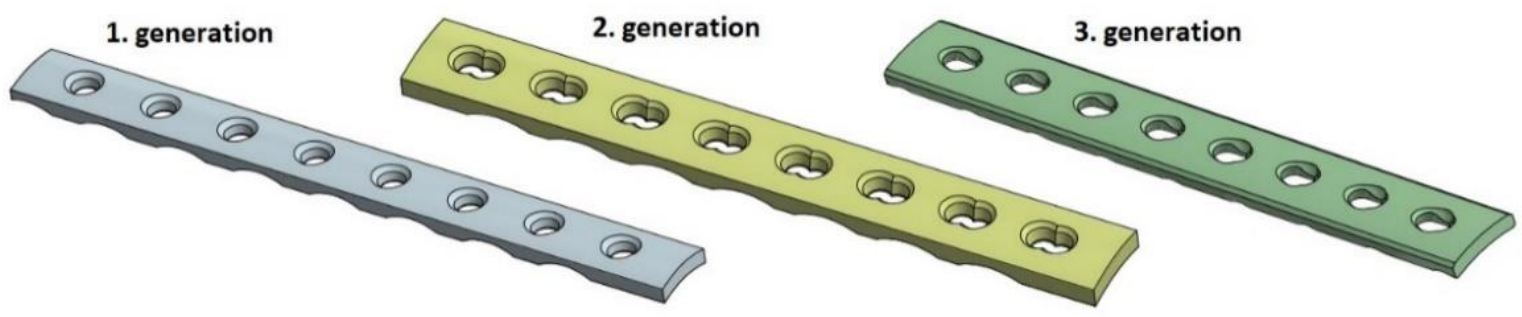

Fig. 2 Models of three generations of bone plates.

After importing the FEA results to fe-safe and after selecting the relevant stress dataset, it was possible to define the required loading scenario. The loading cycle can be defined by two numbers that represent the highest and the lowest loads during one cycle. The stress dataset is multiplied by these numbers. For example, let us consider the stresses caused by a force equal to $1000 \mathrm{~N}$; by multiplying them by 2 and 0.2 we obtain the stresses for a loading cycle with a maximum force equal to $2000 \mathrm{~N}$ and a minimum force equal to $200 \mathrm{~N}$. Thus, it is possible to compute the analysis at several loading levels.

In order to perform the analysis, it was necessary to select a fatigue algorithm and a method for the correction of the mean stress. Two stress-based algorithms were employed: the von Mises algorithm and the Normal Stress algorithm. The von Mises algorithm employs the signed von Mises stress as the damage parameter, while Normal Stress is a critical plane multi-axial algorithm that uses the maximal principal stress. Walker's mean stress correction was used with both algorithms.

\section{Results and discussion}

The results obtained from the fatigue test with the flat samples including the $S$ - $N$ curves are shown in the graph below (see Fig. 3). The crosses represent the destroyed samples and the circles the samples that were not destroyed. The Basquin's model parameters were calculated using only the data on the destroyed samples. The coefficient of determination for the linear regression with the data on the stainless steel was $98.70 \%$ and for the titanium alloy $88.85 \%$.

The results obtained from the fatigue tests with the two generations of bone plates are plotted below in terms of the force amplitude (see Fig. 4), thus allowing for the comparison of 
the differences between the two generations caused by their differing geometries. The firstgeneration bone plates were thinner and narrower than the second-generation plates; therefore, the results for the first-generation bone plates are positioned lower in the graph.

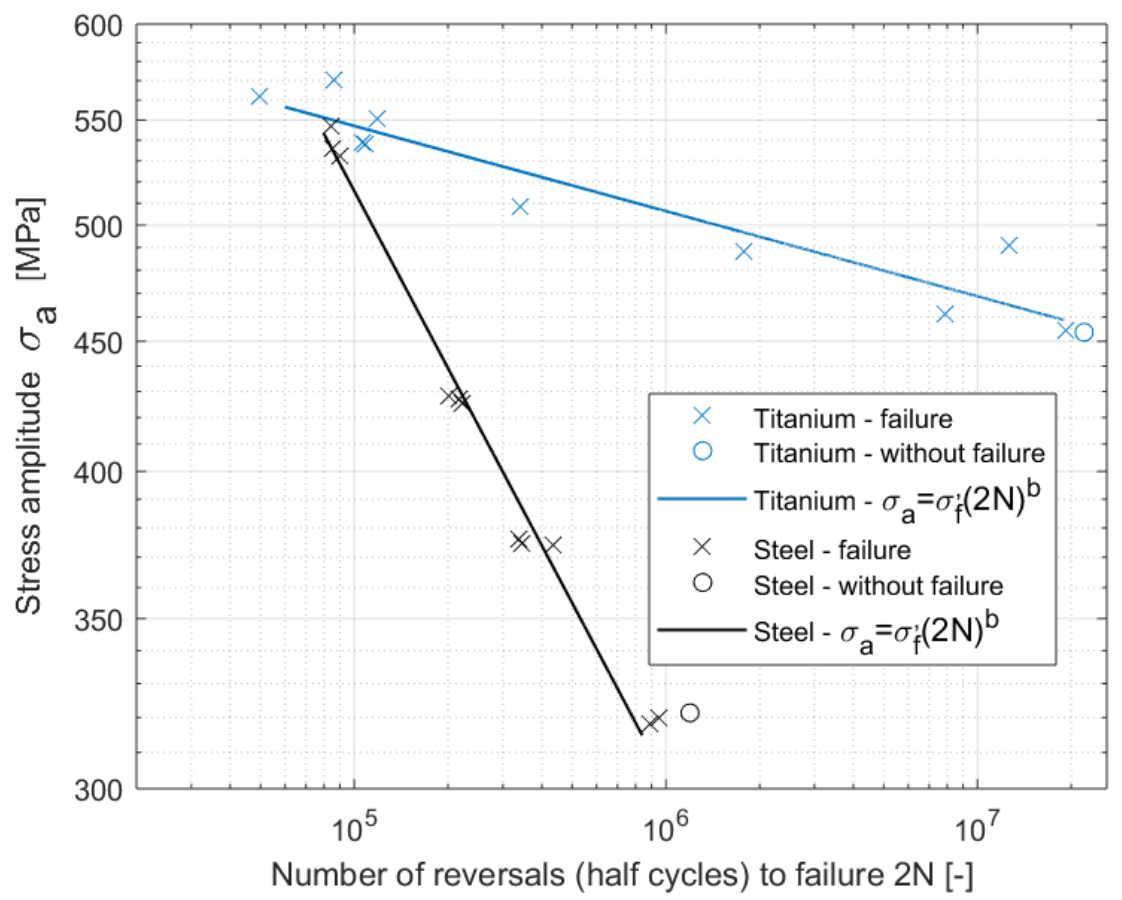

Fig. $3 S-N$ curves for the flat samples made of stainless steel and titanium alloy.

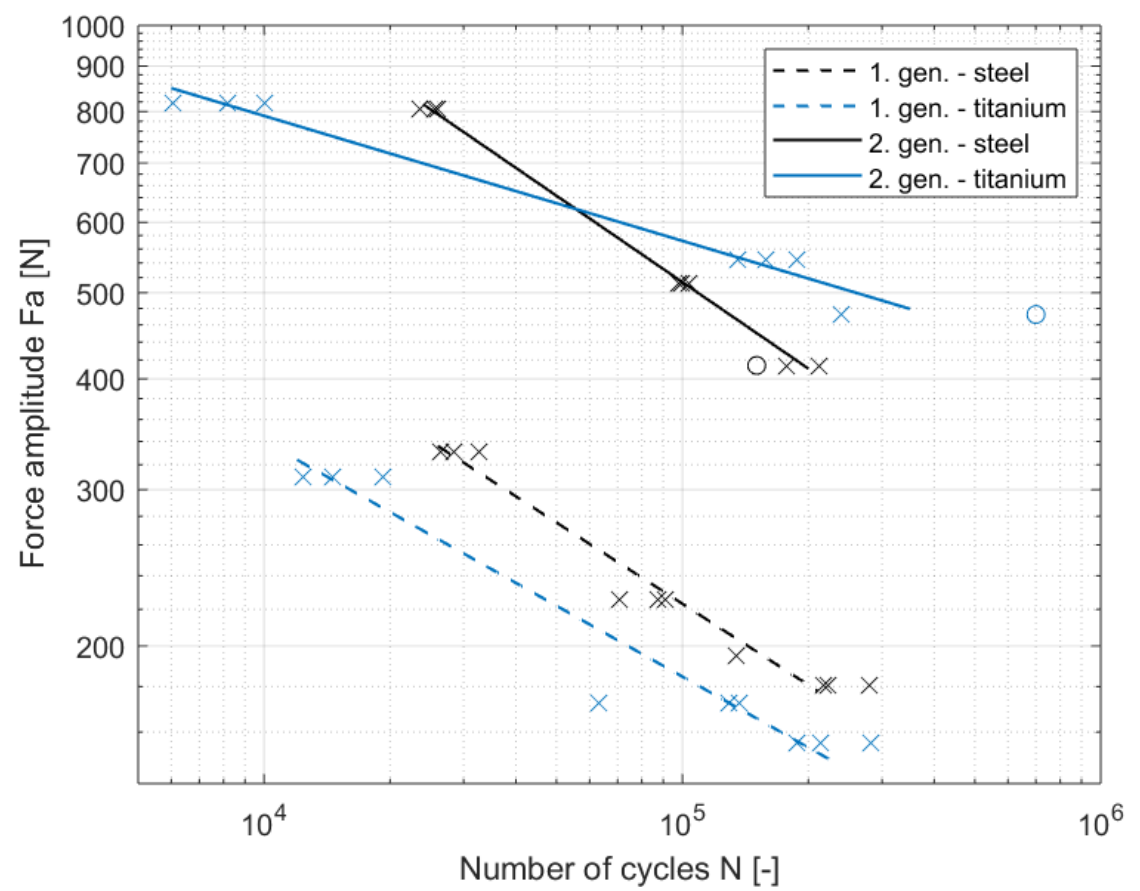

Fig. 4 Measured data for the first and second generations of steel and titanium alloy bone plates.

The material parameters used in the fe-safe analysis are listed below (see Table 1). The table includes the modulus of elasticity $E$, the ultimate tensile strength $R_{m}$, the Walker's equation parameter $\gamma$ [9], the Basquin's model parameters for the fully reversed cycle, and the parameters estimated using Seeger's method (as described in the previous chapter). 
Table 1: Material parameters used in the fe-safe analysis.

\begin{tabular}{|l|c|c|c|c|c|c|c|c|c|}
\hline & $\boldsymbol{E}$ & $\boldsymbol{R}_{\boldsymbol{m}}$ & $\boldsymbol{\gamma}$ & $\boldsymbol{\sigma}_{\boldsymbol{f}}^{\prime}$ & $\boldsymbol{b}$ & $\boldsymbol{K}^{\prime}$ & $\boldsymbol{n}^{\prime}$ & $\boldsymbol{\varepsilon}_{\boldsymbol{f}}^{\prime}$ & $\boldsymbol{c}$ \\
\cline { 2 - 10 } & {$[\mathrm{GPa}]$} & {$[\mathrm{MPa}]$} & {$[-]$} & {$[\mathrm{MPa}]$} & {$[-]$} & {$[\mathrm{MPa}]$} & {$[-]$} & {$[-]$} & {$[-]$} \\
\hline Steel & 168.6 & 935 & 0.66 & 9755 & -0.23 & 14965 & 0.40 & 0.34 & -0.58 \\
\hline Titanium & 112.1 & 925 & 0.54 & 1159 & -0.03 & 1220 & 0.05 & 0.35 & -0.69 \\
\hline
\end{tabular}

The output of the fe-safe analysis comprise the number of cycles calculated for the highest loaded node in the model, in other words the lowest lifetime calculated for the whole part. It was also possible to export the results to the *.odb file format and to display them in Abaqus as a contour plot, which showed the calculated fatigue life for the whole of the model (see Fig. 5).

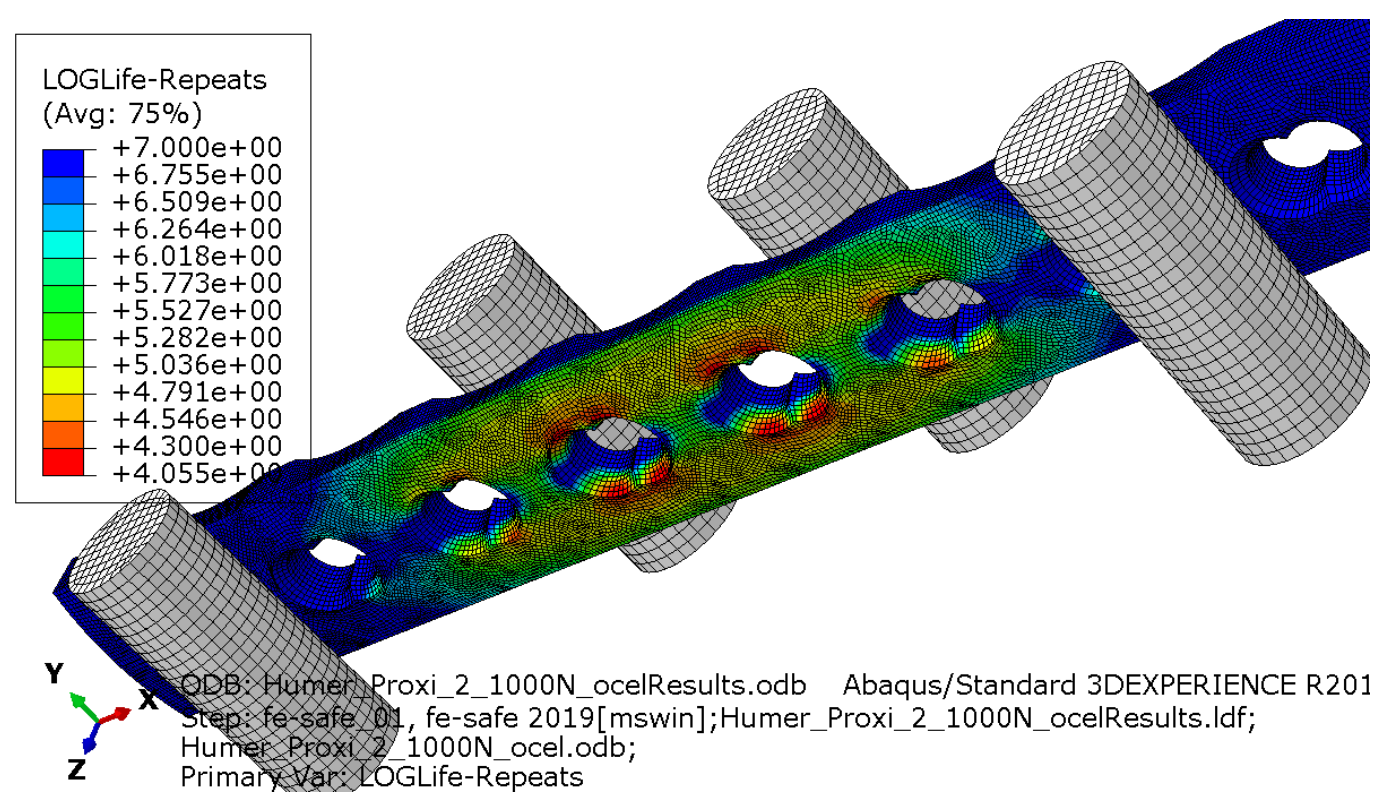

Fig. 5 Results of the fe-safe analysis for the second generation of steel bone plates displayed as a contour plot in Abaqus.

The color scale represents the so-called log-life that can be converted to the number of cycles using $\mathrm{N}=10^{\mathrm{log} \text { life }}$. The contour plot shows that the critical areas with the lowest fatigue life (in red) are located around the holes; this corresponds to the areas with the highest stress. It also corresponds to those areas in which the initiation of fatigue cracking occurred during the fatigue experiments.

The fe-safe analysis was conducted for three generations of bone plates in two material variants. The predictions for each of the models were determined in the same force amplitude range as that in which the experiments were performed. Fig. and Fig. provide a comparison of the fe-safe prediction results and the results of the fatigue experiments plotted in terms of the force amplitude. The experimental results are displayed as thick lines and the prediction results as thinner lines; the graph provides the results of both the algorithms applied: the von Mises (VM) and Normal Stress (NS) algorithms. Predictions were determined for three generations of bone plates, whereas the experiments considered the first and second generations of bone plates only. The prediction for the third generation lies between those for the first and second generations, which corresponds to its geometry, i.e. a compromise between the first and second generations. 


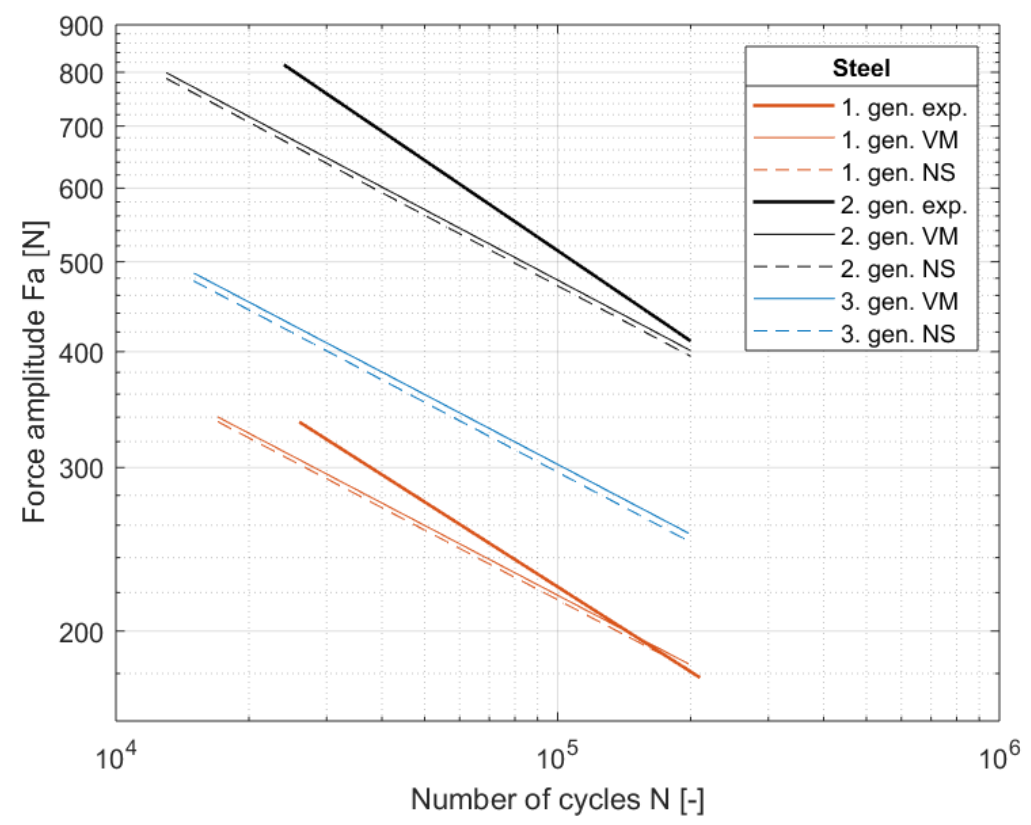

Fig. 6 Comparison of the experimental and fe-safe results for all the generations in terms of the force amplitude - stainless steel.

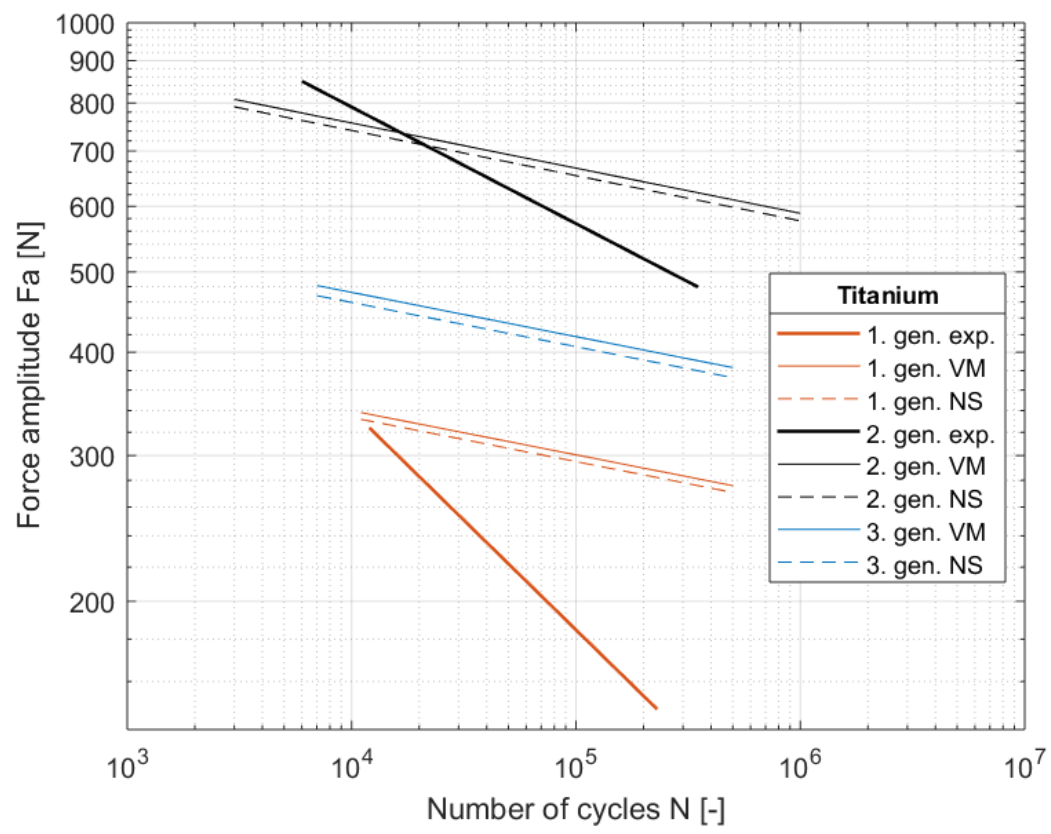

Fig. 7 Comparison of the experimental and fe-safe results for all the generations in terms of the force amplitude - titanium alloy.

Fig. 8 and Fig. 9 display the same results plotted in terms of the stress amplitude. When the results are presented in this form, the geometry of the bone plate is no longer considered. Therefore, the predictions show the same results for all the generations. The stress amplitudes were computed from the force amplitudes using the FEA results from Abaqus. The highest stress amplitudes in the whole of the model were used for a given force; hence, the $S-N$ curves are related to the areas around the holes in which the highest stress occurs. The graphs also illustrate that the predictions calculated using the two different algorithms are relatively similar. 
The fe-safe prediction for the steel is relatively accurate, although it predicts a lower fatigue life, especially for the higher stress amplitudes. However, the prediction results for the third generation compared to the prediction and experimental results for the first and second generations (see Fig. 6) reveals where the results of the experiment with the third generation could be expected.

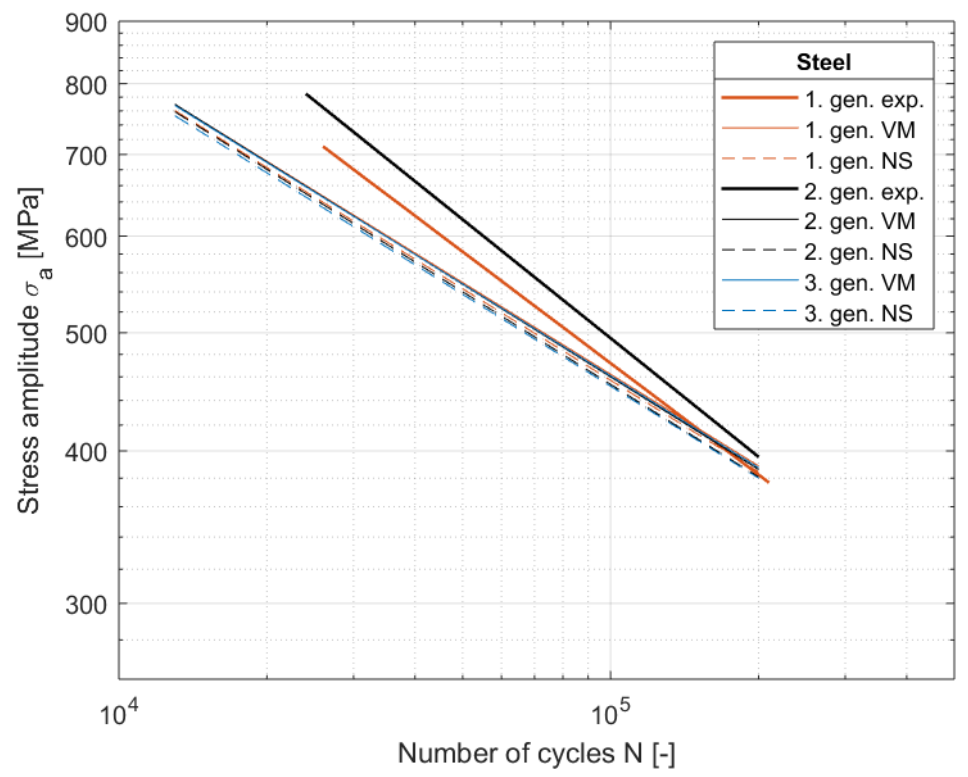

Fig. 8 Comparison of the experimental and fe-safe results for all the generations in terms of the stress amplitude - stainless steel.

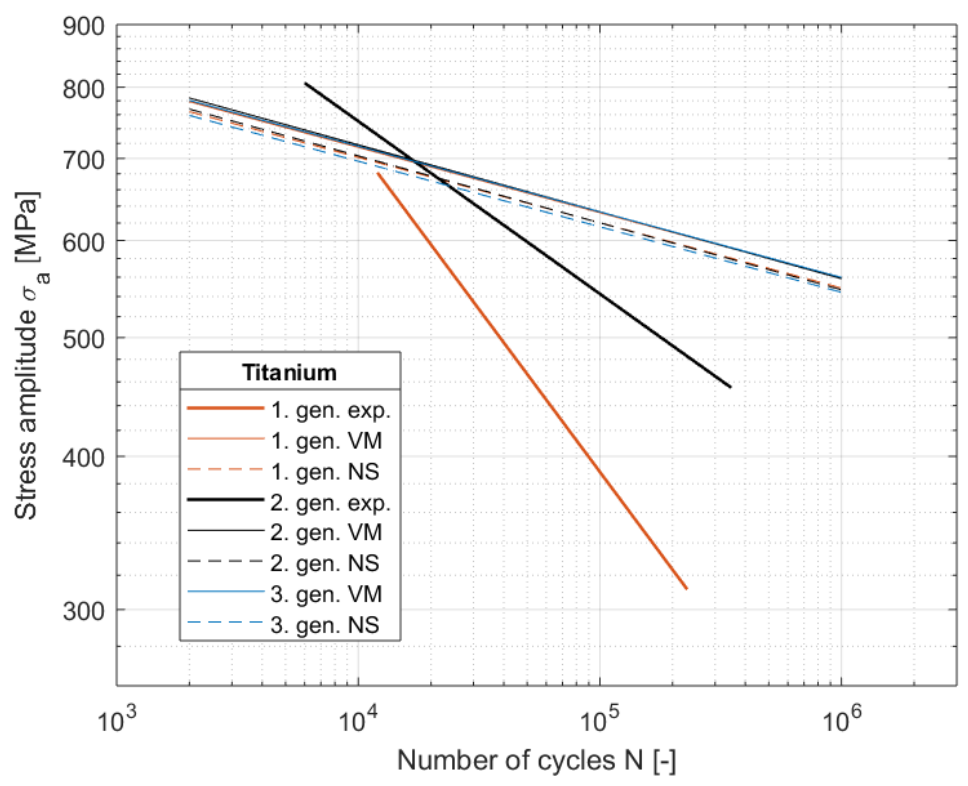

Fig. 9 Comparison of the experimental and fe-safe results

for all the generations in terms of the stress amplitude - titanium alloy.

The results of the prediction for the titanium alloy clearly do not correspond well to the experimental results, which may have been due to input material parameters which were computed with a lower coefficient of determination for titanium alloy. It is also possible to observe that the $S-N$ curves from the experiments on the two generations of titanium alloy bone plates (see Fig. 9) differ more than do the $S$ - $N$ curves for the steel bone plates (see Fig. 
8); this may indicate fluctuations in terms of the quality of the titanium alloy used in the production of the two generations of bone plates.

\section{CONCLUSION}

SIMULIA fe-safe software was used for the prediction of the fatigue life of bone plates for humeral proximal fractures. The prediction was based on the FEA results from Abaqus and the material parameters determined experimentally. The experiments were performed on samples of 1.4441 (ASTM F138) stainless steel for implants and Ti6Al4V ELI (ASTM F136) titanium alloy. The fe-safe analysis results were compared with the measured data obtained from the bone plate fatigue tests. Although the correspondence between the prediction and the experimental results for the titanium alloy was poor, the prediction results for the stainless steel were relatively accurate and we suggest that they can be used to estimate the fatigue life of bone plates with differing geometries.

\section{ACKNOWLEDGEMENTS}

This study was supported via a grant project awarded by the Technology Agency of the Czech Republic, No. TACR TH03010418.

\section{REFERENCES}

[1] Wan, B., Entezari, A., Zhang, Z. et al. "On fatigue failure prediction of prosthetic devices through XFEM analysis", International Journal of Fatigue 147, 2021, DOI: 10.1016/j.ijfatigue.2021.106160

[2] Logroscino, G., Donati, F., Saracco, M., Pilloni, L., Piconi, C. "Early failure of a locked titanium plate in a proximal humeral fracture: Case report and metallurgic analysis", Trauma Case Reports 17, pp. 18 - 22, 2018. [cit. 2021-04-11]. ISSN 23526440. Available from: DOI: 10.1016/j.tcr.2018.09.005

[3] Trebuňa, F., Bocko J., Pástor, M., Lengvarský, P., Prada, E. "The Finite Element Analysis of High Precision Positioning System", Strojnícky casopis - Journal of Mechanical Engineering 68 (4), pp. 41 - 48, 2018. DOI: 10.2478/scjme-2018-0045

[4] Łagoda, A., Niesony, A. "Stress Analysis of Dental Implant Inserted in the Mandible", Strojnícky časopis - Journal of Mechanical Engineering 68 (1), pp. 25 - 32, 2018. DOI: 10.2478/scjme-2018-0003

[5] ASTM F382-17. "Standard Specification and Test Method for Metallic Bone Plates", West Conshohocken, PA: ASTM International, 2017.

[6] ČSN EN ISO 6892-1. "Kovové materiály - Zkoušení tahem - Část 1: Zkušební metoda za pokojové teploty", Praha: Úřad pro technickou normalizaci, metrologii a státní zkušebnictví, 2017, 76 p.

[7] “1.4441/AISI 316L-Austenitic stainless steel for implants datasheet", Kleinmetals Available from: http://www.kleinmetals.ch/shop/Datenblatt/E/555.pdf

[8] "TITAN Grade 23 TiAl6V4 ELI datasheet", Kleinmetals Available from: http://www.kleinmetals.ch/shop/Datenblatt/E/705.pdf

[9] Dowling, N. E., Calhoun, C. A., Arcari, A. "Mean stress effects in stress-life fatigue and the Walker equation", Fatigue \& Fracture of Engineering Materials \& Structures 32 (3), pp. 163 - 179, 2009. DOI: 10.1111/j.1460-2695.2008.01322.x

[10] "Strain Based Fatigue Analysis", Autodesk help, Available from: http://help.autodesk.com/view/ASMECH/2014/ENU/?guid=GUID-ECDCD9AB-BE6543A3-9ECB-D25C38606A3E 